\title{
SYNTHESIS AND CHARACTERIZATION OF Si OXIDE COATED NANO CERIA BY HYDROLYSIS, AND HYDROTHERMAL TREATMENT AT LOW TEMPERATURE
}

\begin{abstract}
The purpose of this work was to the application of $\mathrm{Si}$ oxide coatings. This study deals with the preparation of ceria $\left(\mathrm{CeO}_{2}\right)$ nanoparticles coating with $\mathrm{SiO}_{2}$ by water glass and hydrolysis reaction. First, the low temperature hydro-reactions were carried out at $30 \sim 100^{\circ} \mathrm{C}$. Second, Silicon oxide-coated Nano compounds were obtained by the catalyzing synthesis. $\mathrm{CeO}_{2} \mathrm{Nano}^{\circ}$ powders have been successfully synthesized by means of the hydrothermal method, in a low temperature range of $100 \sim 200^{\circ} \mathrm{C}$. In order to investigate the structure and morphology of the Nano-powders, scanning electron microscopy(SEM) and X-ray diffraction(XRD) were employed. The XRD results revealed the amorphous nature of silica nanoparticles. To analyze the quantity and properties of the compounds coated with Si oxide, transmission electron microscopy(TEM) in conjunction with electron dispersive spectroscopy was used. Finally, it is suggested that the simple growth process is more favorable mechanism than the solution/aggregation process.

Keywords: Nano-particle, Water glass, Hydro-reaction, Coating method
\end{abstract}

\section{Introduction}

Recent nanotechnology and nano-structures have been intensively developed in combination with techniques for the development of synthetic method having a size ranging from several nanometers to a few hundred nanometers, using various types of nanostructure manufacturing processes and applications, such as nanorods and photonic crystal $[1-4,16]$. In recent years, nano-structures have attracted much attention due to their potential applications in fabricating nanometer-scale devices possessing a variety of interesting functions [5,6]. Among the methods used to coat the nano-structures to protect against wear and to provide corrosion resistance, a number of researchers have used Si oxide to provide functionality to nano-powders for surface treatment $[7,8]$. Coatings of various types of materials for nanoparticles such as nano-scale structures, nano-rods, and nano-belts and nano-plates have been used $[9,10]$. These functional surface treatments have gradually extended the range of applications for the purpose of improving the corrosion resistance of nano-compounds, to change the surface appearance, improve the wear resistance, and improve the lubricity of nano-materials, changing a variety of functional properties of the materials. In addition, the sol-gel method, a synthetic method for forming the coating of the film, has often been used. Si oxide can serve as a chemically protective film on the surface in order to improve the chemical durability of the nano-compound and is coated onto the nano-compound using water-glass hydrolysis. Since $\mathrm{Si}$ is an oxide, we significantly modified the surface of the $\mathrm{SiO}_{2}$ film material which was employed in this study [11,12]. Ceria $\left(\mathrm{CeO}_{2}\right)$ has been widely used as a solid ion conductor and as a catalyst carrier, as it is a heat resistant material with a high melting temperature of $2477^{\circ} \mathrm{C}$. In particular, ceria has a high chemical resistance in acids and bases and can thus be used in acidic and basic binders/suspensions. Many studies have been carried out on nano-powders to increase their oxidation potential in a state of grain growth and to prevent surface area increase due to further oxidation of the powder surface as well as to improve their chemical durability and control their grain growth.

In this study, the hydrothermal synthesis method is used for the coating of the $\mathrm{Si}$ oxide $\mathrm{CeO}_{2}$, as it is a simple method with a low cost implementation. Hydrothermal synthesis is then used rapidly and easily for the solvent. Creating the nanostructure in this way was suitable for application in the study. The features of this approach are effective application, and improved degree of coating adhesion of the Si oxide, providing solubility in the solvent by increasing the temperature. The system is pressurized as close to the critical point as possible for most of the material.

\section{Experimental}

The $\mathrm{pH}$ of the water glass $\left(\mathrm{Na}_{2} \mathrm{SiO}_{2} 4 \mathrm{H}_{2} \mathrm{O}\right)$ at room temperature was $\mathrm{pH}=12 \sim 12.5$ after placing $0.1 \mathrm{~N}$ in the water glass to coat the $\mathrm{Si}$ oxide at $80^{\circ} \mathrm{C}$. The $\mathrm{pH}=10 \sim 12$ was achieved by

\footnotetext{
BD CENTER, KTD C\&S CO.,LTD., INCHEON 21687, REPUBLIC OF KOREA

** DIVISION OF MATERIALS SCIENCE AND ENGINEERING, HANYANG UNIVERSITY, SEOUL 04763, REPUBLIC OF KOREA 
mixing the colloidal solution on ceria $\left(\mathrm{CeO}_{2}\right)$ for $10 \sim 20 \mathrm{~min}$ at $100 \sim 200^{\circ} \mathrm{C}$ using a magnetic stirrer. By hydrolyzing, the waterglass was subjected to hydrothermal synthesis by utilizing the equipment shown in Fig. 1. Also, the mixed aqueous solution was later used as a coating by filtering the solution using filter paper, washing several times, and then drying for 12 hours in a drying oven to provide a Si oxide coating of ceria in a dried rigid state. The solution was then ball milled to become a powdery nano-ceria composite powder. The Si oxide coating process is presented as a schematic diagram in Fig. 2 [13]. In addition, the coated powder was subjected to heat treatment for $30 \mathrm{~min}$ at atmospheric pressure to $500^{\circ} \mathrm{C}$, to determine the denseness of the surface of the film type and the precipitated microstructures.

Scanning Electron Microscopy (SEM, Hitachi S - 4200) was performed to observe the shape, size, etc. of the coated film on the Si Ceria. The TEM specimens were ultrasonically cleaned by immersing in an acetone solution. X-ray Diffraction Analysis (DMAX 2500 with $\mathrm{Cu}-\mathrm{K} \alpha$ radiation) was carried out in order to determine the precipitated structure and components of the specimen.

\section{Results and discussion}

The SEM-EDS analysis results for observing the nanostructure coating and the type of coating of $\mathrm{SiO}_{2}$ on Ceria show that the $\mathrm{Si}$ and the oxide are present on the surface, as shown in Fig. 3.

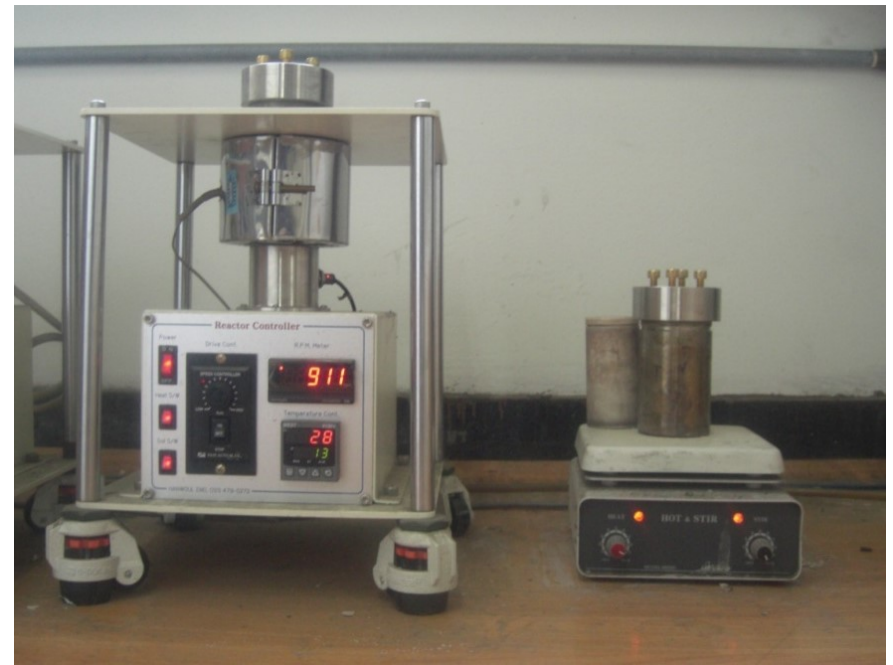

Fig. 1. Equipment used for hydrolysis and hydrothermal processes

The following formula was used to theoretically verify this.

$$
\begin{array}{ll}
2 \mathrm{Na}_{2} \mathrm{SiO}_{2} 4 \mathrm{H}_{2} \mathrm{O}+2 \mathrm{H}_{2} \mathrm{O}+ & \\
+\mathrm{O}_{2} \rightarrow 4 \mathrm{Na}^{+}+4 \mathrm{OH}^{-}+2 \mathrm{Si}(\mathrm{OH})_{4} & \text { at } \mathrm{pH}=12.5 \\
2 \mathrm{Si}(\mathrm{OH})_{4} \rightarrow 2 \mathrm{SiO}_{2}+2 \mathrm{H}_{2} \mathrm{O} & \text { at } \mathrm{pH}=11
\end{array}
$$

When a $\mathrm{Na}_{2} \mathrm{SiO}_{2} 4 \mathrm{H}_{2} \mathrm{O}$ was added to the first water-glass solution in the hydrolysis zone outside the neutral area, the alkaline $\mathrm{pH}=12.5$ is maintained. $\mathrm{A} 2 \mathrm{Si}(\mathrm{OH})_{4}$ is used as a hydrolysis zone

\section{Procedure A}

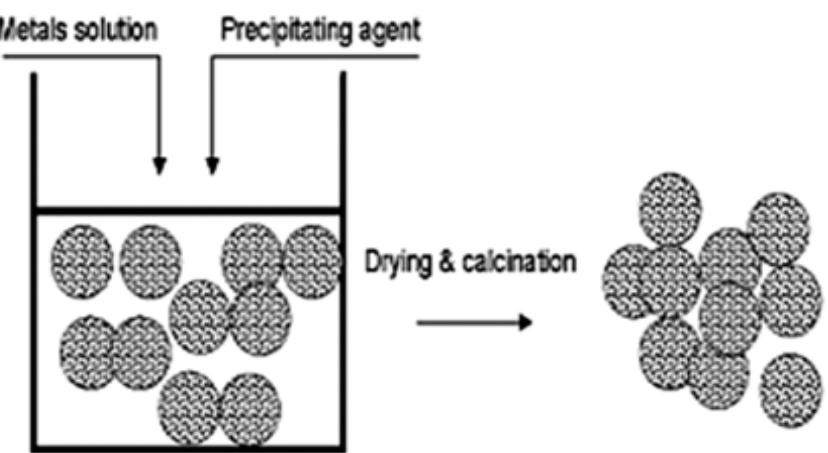

(a)

\section{Procedure B}

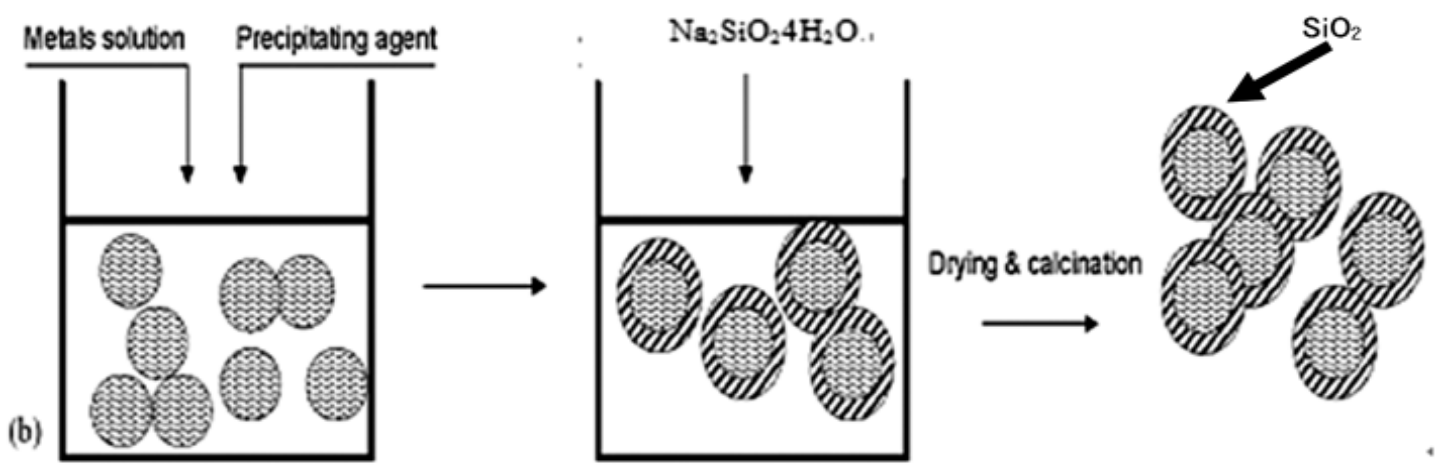

Fig. 2. Schematic illustration of synthesis of Ceria coated with $\mathrm{SiO}_{2}$. (a) the simultaneous co-precipitation, and (b) the sequential precipitation of $\mathrm{SiO}_{2}$ coating process 


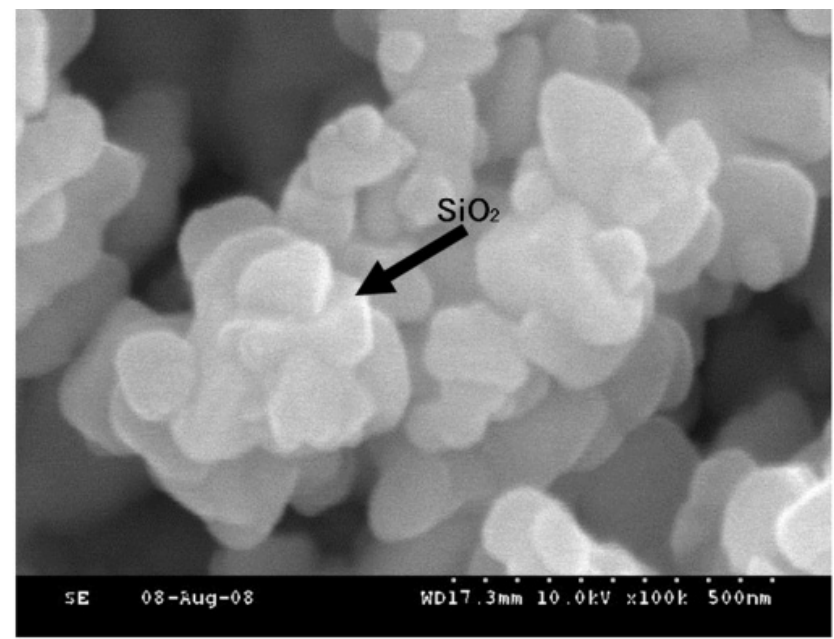

(a)

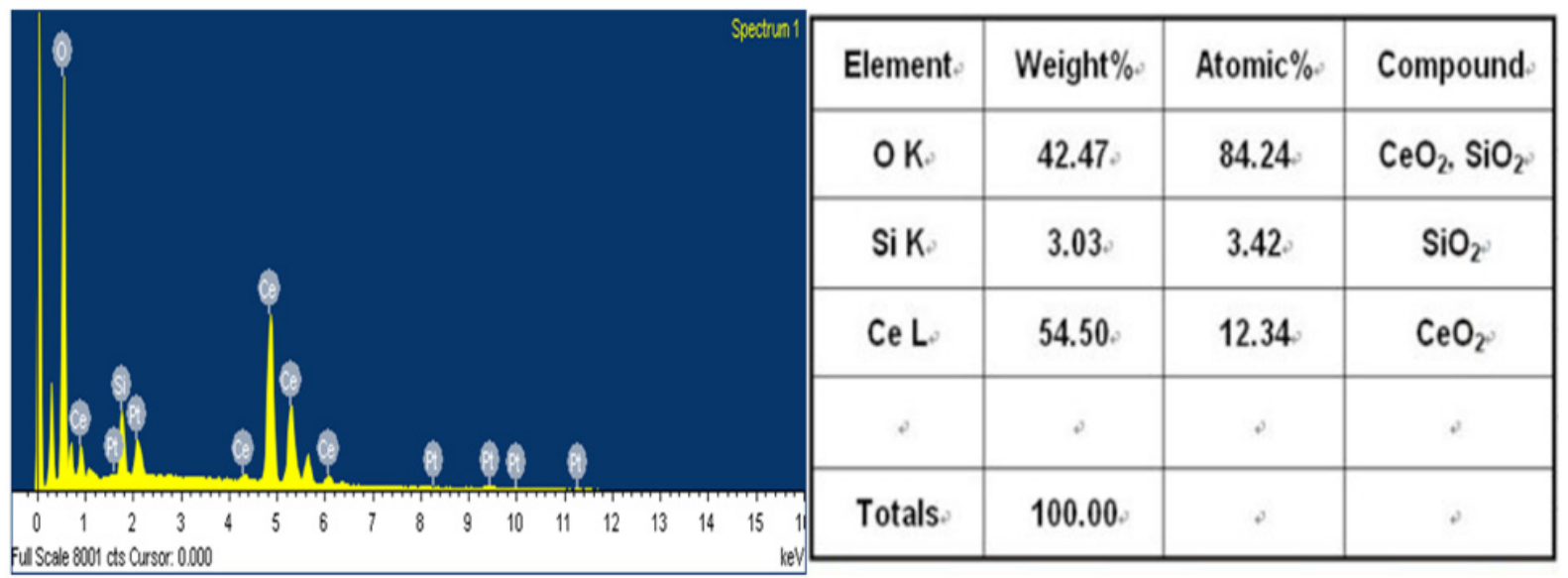

(b)

Fig. 3. (a) SEM image and (b) EDS results of $\mathrm{SiO}_{2}$-coated ceria

and separated to the polymerize coating in the form of a range which is held by $\mathrm{pH}=11$. And then, oxides of Si single molecules then cover the surface of the nano-compounds $[14,15]$.

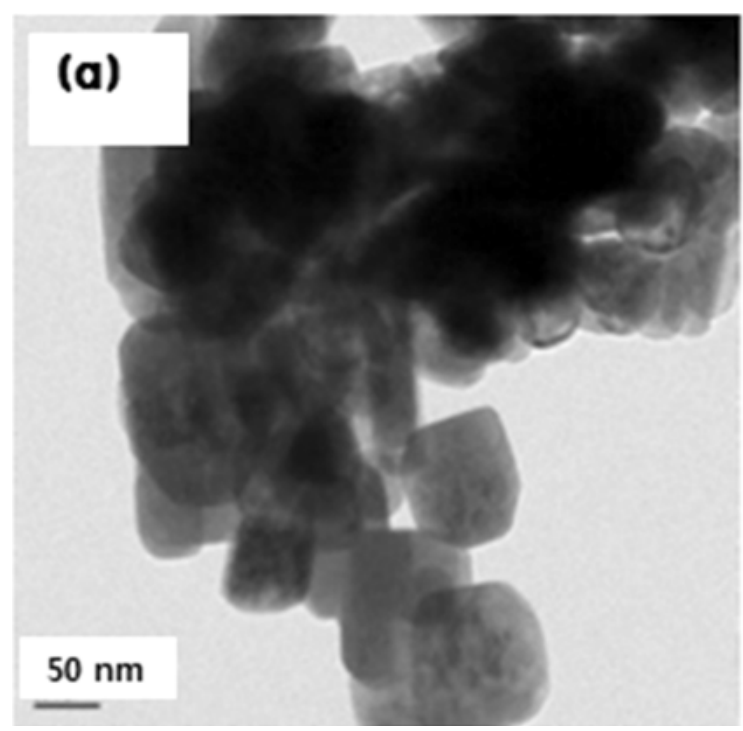

In Figure 4, the surface state is shown before and after covering with the $\mathrm{Si}$ oxide coating. A change in the size and composition of the $\mathrm{SiO}_{2}$ was observed due to heat treatment at

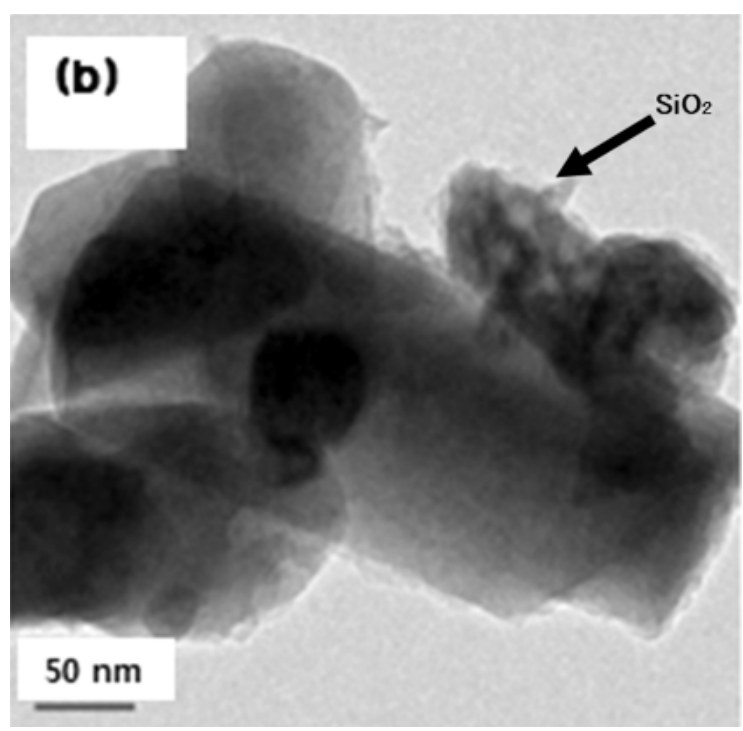

Fig. 4. TEM images of (a) uncoated and (b) $\mathrm{SiO}_{2}$-coated ceria 


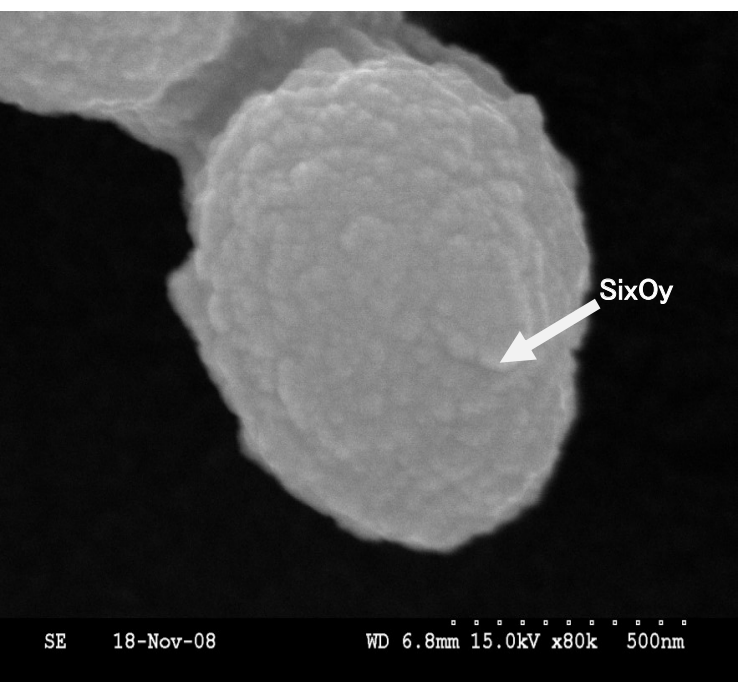

(a)

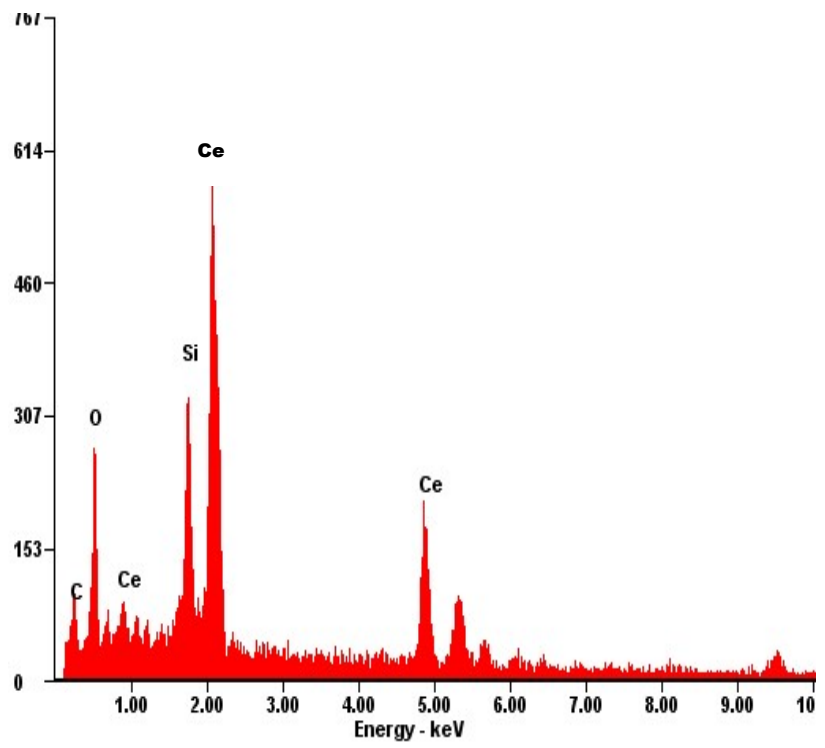

(b)

Fig. 5. (a) SEM images and (b) EDS results of $\mathrm{SiO}_{2}$ coated ceria annealed at $500^{\circ} \mathrm{C}$

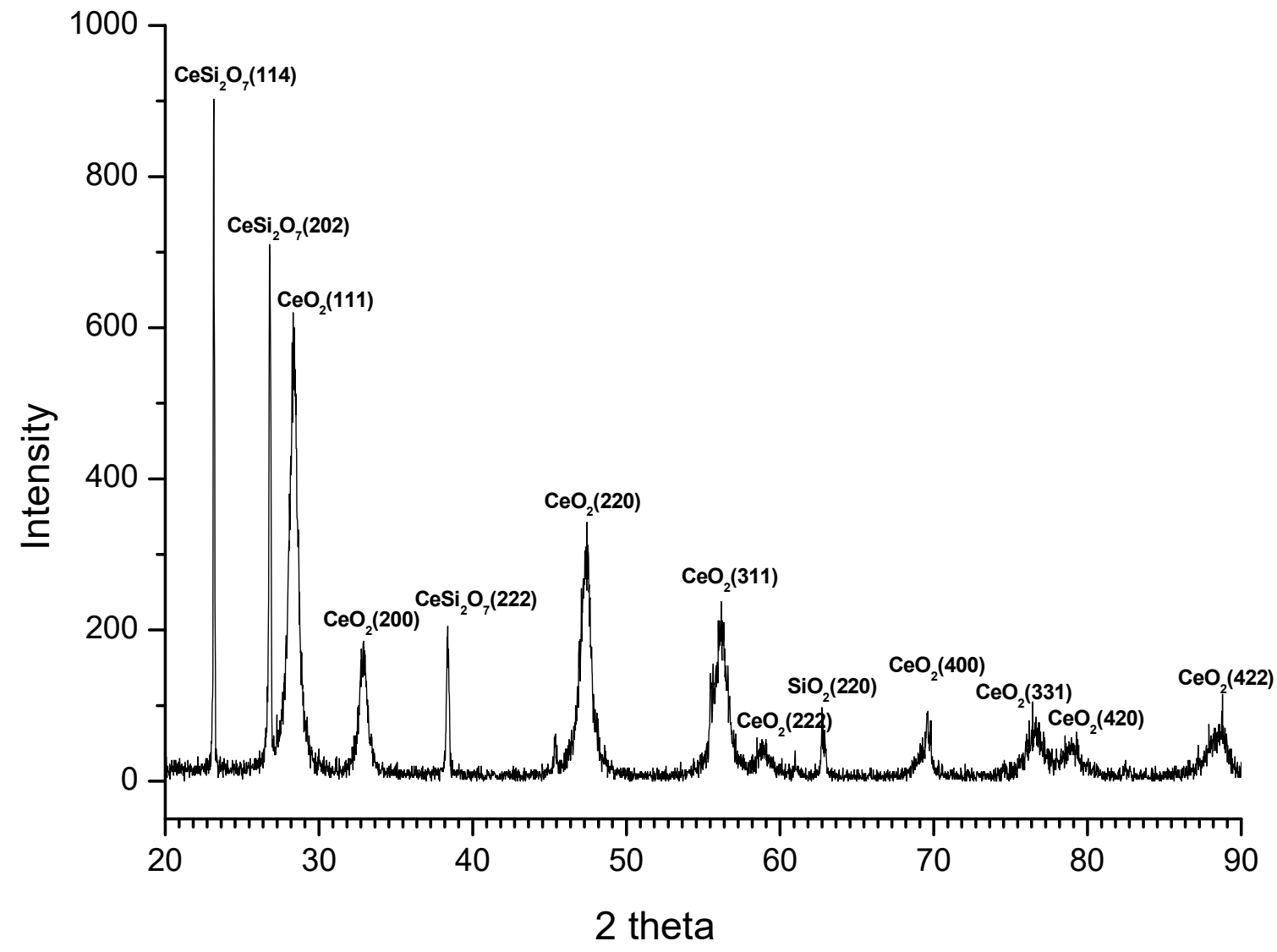

Fig. 6. XRD pattern of $\mathrm{CeO}_{2}$ nano particles coated with $\mathrm{SiO}_{2}$ and annealed at $500^{\circ} \mathrm{C}$

a high temperature for the coated Ceria. In the observation results shown in Fig. 5, the SEM images show that after heat treatment at $500^{\circ} \mathrm{C}$ for $30 \mathrm{~min}$, the grain growth and the level of $500 \mathrm{~nm}$ were maintained even without the glass film covering the surface. The state of the particle after heat treatment at $500^{\circ} \mathrm{C}$ for $30 \mathrm{~min}$ showed a rapidly increased size with the existing thickness of $500 \mathrm{~nm}$. The result shows that the protective function of the $\mathrm{Si}$ oxide was weak in accordance with the temperature increase. That is, the XRD analysis results shown in Fig. 6 demonstrate that the components of the composite qualitatively $\mathrm{CeSi}_{2} \mathrm{O}_{7}$ at $500^{\circ} \mathrm{C}$. It can be seen that the $\mathrm{CeSi}_{2} \mathrm{O}_{7}$ composite coating film is formed after heat treatment for $30 \mathrm{~min}$. This demonstrates that as a new compound, $\mathrm{CeSi}_{2} \mathrm{O}_{7}$ is generated by heat treatment showing that the $\mathrm{SiO}_{2}$ reacts with the outer surface of $\mathrm{CeO}_{2}$ nano-powders. 


\section{Conclusions}

In this study, it was confirmed that a water glass solution of Ceria nano-powder formed by hydrolysis and hydrothermal synthesis was impregnated in an aqueous solution to form a film thickness of the $\mathrm{SiO}_{2}$ coating of $5 \sim 50 \mathrm{~nm}$. $\mathrm{CeO}_{2}-\mathrm{SiO}_{2}$ nanopowder was shown to be an effective composite coating film that can be formed at high temperature through heat treatment at $500^{\circ} \mathrm{C}$. Finally, it is suggested that the simple growth process is a more favorable mechanism than the solution/aggregation process. And then, I have achieved the protection of chemical corrosion against to strong acid or strong bases by the nano-ceria coated with $\mathrm{Si}$ oxide. As well, I have acquired anti-abrasive properties by $\mathrm{CeSi}_{2} \mathrm{O}_{7}$ composite layers.

\section{REFERENCES}

[1] Y. Zhang, K. Suenage, C. Colliex, S. Iijima, Science 281, 973 (1998).

[2] R. Zhang, Y. Lifshitz, S. Lee, Adv. Mater. 15, 635 (2003).
[3] Y. Li, Y. Bando, D. Golberg, Y. Uemura, Appl. Phys. Lett. 83, 3999 (2003).

[4] Y. Yin, Y. Lu, Y. Sun, Y. Xia, Nano Lett. 2, 427 (2002).

[5] Y. Wang, Z. Tang, X. Liang, N. Liz-Marzan Kotov, Nano Lett. 4, 225 (2004).

[6] M. Ahmad, T. Khan, G. Ali, J. Akhter, Rev. Adv. Mater. Sci. 51, 427 (2006).

[7] H. Gleiter, Prog. Mater. Sci. 33, 223 (1989).

[8] Y. Lu, Mat. Sci. Eng. R. 16, 161 (1996).

[9] M. Meyers, A. Mishra and D. Benson, Prog. Mater. Sci. 26, 43 (2010).

[10] R. Ormerod, Chem. Soc. Rev. 32, 17 (2003).

[11] A. Hetznecker, H. Kohler, U. Schonauer, U. Guth, Sensor and Actuators B: Chemical 99, 373 (2004).

[12] E.C. Ziemath, B.Z. Saggioro, J.S. Fossa, J. of Non-Crystalline Solids 351, 3870 (2005).

[13] X. Li, Z. Cao, Z. Zhang, H. Dang, Applied Surface Science 252, 7856 (2006)

[14] Z. Guo, F. Du, G. Li, Z. Cui, Inorganic Chemistry 45, 4167 (2006).

[15] Q. Fang, X. Liang, R.S.C Adv. 2, 5370 (2012).

[16] Y. Liu, G. Zhao, D. Wang, Y. Li, National Science Review 2, 150 (2015). 